\title{
A Quarter Century's Experience with Intra- operative Nerve Action Potential Recording
}

\author{
David G. Kline and Leo T. Happel
}

\begin{abstract}
The rationale, basic considerations, and technique of intraoperative nerve action potential (NAP) recording have been reviewed. Experience using this technique in several thousand patients over a 25 year period has been summarized. The most frequent serious nerve injury is one that leaves it in continuity. Resection of such a lesion that is regenerating does the patient a great disservice as does exploration without repair of one with little or no potential for useful spontaneous recovery. The frequency of lesions in continuity as well as the difficulties in evaluating them in the early months by electromyography let alone by surgical inspection has led to the development of intraoperative NAP recording. Where neurolysis was based on a recordable NAP across a lesion in continuity, 93\% recovered good function. Where resection of the lesion was based on absence of an NAP, the injury was, without exception, neurotmetic and/or one with poor potential for useful recovery without repair. Some lesions had an NAP across their lesion but a portion of the cross-sectional area appeared more seriously injured. By use of NAP recordings, a split repair was done and usually with good results.
\end{abstract}

\begin{abstract}
RÉSUMÉ: Expérience d'un quart de siècle avec l'enregistrement peropératoire des potentiels d'action nerveux. La justification, les considérations de base et la technique de l'enregistrement peropératoire des potentiels d'action nerveux (PAN) ont été revues. L'experience d'utilisation de cette technique chez plusieurs milliers de patients sur une période de 25 ans a été résumée. Le dommage nerveux sévère le plus fréquent est celui qui laisse le tissu nerveux en continuité. La résection d'une telle lésion qui est en régénération fait davantage de tort au patient. Il en est de même pour l'exploration sans réparation chez le patient qui a peu ou pas de potentiel de récupération spontanée. La fréquence des lésions en continuité, comme les difficultés rencontrées dans leur évaluation dans les premiers mois par l'électromyographie, et davantage par l'inspection chirurgicale, a conduit au développement de l'enregistrement peropératoire des PAN. Quand la neurolyse était basée sur des PAN enregistrables à travers une lésion en continuité, 93\% des sujets ont récupéré une bonne fonction. Quand une résection de la lésion était basée sur l'absence de PAN, la lésion était, sans exception, neurotmétique et/ou une lésion dont le potentiel de récupération utile était faible sans réparation. Certaines lésions avaient un PAN à travers la lésion, mais une portion de la reegion évaluée en coupe transversale semblait plus sévèrement lésée. En utilisant des enregistrements PAN, une réparation après section a été effectuée avec de bons résultats dans la plupart des case.
\end{abstract}

Can. J. Neurol. Sci. 1993; 20:3-10

The majority of nerve injuries leading to serious loss of function do not transect nerve but instead leave it in continuity. ${ }^{1.2}$ Estimates for incidence of such lesions in continuity vary in different nerve injury series and depend somewhat on how blunt the injury mechanisms reported are.$^{3,4}$ Since blunt injuries affecting nerve are much more frequent than sharp ones, the majority of serious injuries to nerve produce lesions in continuity. Thus, most series show a 60 to $70 \%$ incidence of lesions in continuity amongst seriously injured nerves. ${ }^{5}$

If left alone, eventual outcome of these lesions in continuity is variable. Some recover nearly completely, others have partial recovery but less than a surgical repair might have provided and still others recover poorly or not at all. This is because there is a variable amount of distortion of the internal neural and connective tissue architecture with such lesions. ${ }^{6.7}$ Some lesions have a large element of neurapraxic block or axonotmetic change to fibers which permits good spontaneous recovery or regrowth. Other lesions in continuity, although in gross continuity, have a predominant amount of or total neurotmetic change that does not permit functional regeneration. The presumption then that physical continuity ensures spontaneous recovery is false. Equally false is the presumption that complete loss of function distal to such a lesion precludes spontaneous recovery without surgery.

From the Department of Neurosurgery, LSU School of Medicine, New Orleans, Louisiana

Received July 2, 1992. Accepted in final form October 16, 1992

This paper was presented in part, by Dr. Kline, as the Penfield Lecture to the Canadian Congress of Neurological Sciences, Halifax, Nova Scotia, June, 1991 Reprint requests to: Dr. David G. Kline, Department of Neurosurgery, LSUMC, Charity and Ochsner Hospitals, 1542 Tulane Avenue, New Orleans, Louisiana, U.S.A. 70112 


\section{EARLY APPLIED NAP WORK}

During 1962 and 1963 the senior author, while at Walter Reed, reviewed the Lyons-Woodhall slide collection of nerve injuries resected during World War II. ${ }^{8}$ This review reconfirmed one of the most important points made by Woodhall, Nulsen, White and Davis. ${ }^{9}$ There were lesions which looked severe to the operating surgeon which were resected and yet to histologic study had already had excellent and often organized regeneration. One would have predicted that had the lesion been left alone, such regeneration might have led to an adequate functional result without repair. At the same time, one could infer from the review, that there were also a number of lesions in continuity left unresected because they "looked good" that should have been resected.

One method of managing such lesions in continuity might be to follow them clinically and by electromyography (EMG) until it was obvious that adequate recovery was or was not occurring. ${ }^{10}$ For many human injuries other than those very distal in the extremity such as at wrist or ankle, this would mean waiting 6 to 18 months before making a decision for or against surgery. ${ }^{11.12}$ This is because both clinical examination and classic EMG testing measure more terminal axonal input, usually to muscle. Recovery may be suspected because of relatively early contraction of proximal muscles or electrical reversal of deinnervational changes and/or onset of nascent electrical activity. ${ }^{13}$ For many proximal neural injuries even these early clinical and electrical signs may take many months to occur. For example, buttock or hip level injury of sciatic nerve even if axonotmetic may not show early plantar flexion or reversal of dennervational changes in gastrocnemius-soleus for 12 to 18 months. If repair was eventually found to be necessary in these cases, results would be less than could be achieved had repair been done earlier. This is because results of nerve repairs done in the early months after injury are better than those in patients repaired later. In addition, there is still the not uncommon situation of finding at exploration the nerve to be pulled apart despite the fact that the mechanism of injury, because it was blunt, suggested some physical continuity to the lesion.

Muscle contraction in response to direct nerve stimulation can antedate voluntary contraction of muscle for weeks, but for most serious injuries to nerves, this requires many months to be useful. This is because many hundreds to thousands of fibers must have reached muscle and some axonal to motor end-plate reconstruction must have occurred before stimulation produces muscle function that can be seen and/or palpated. There is also the occasional case where only a portion of distal stump nerve fibers reach some muscle fibers. As a result, some function can be stimulated and either seen or recorded by EMG needle and yet further function does not eventuate because the remainder of the fibers are too seriously involved at the injury site. ${ }^{13}$ Nontheless, use of stimulation is an important advance because in some settings it can provide information about regrowth before clinical or EMG examination. ${ }^{14}$

It was evident to the author while at the Walter Reed Army Institute of Research (WRAIR) and under the guidance of George Hayes and Ludwig Kempe that what was needed was an earlier in vivo test for effective regeneration through a lesion in continuity. This test would have to provide reliable information in the early months post injury when neither clinical nor elec- tromyographic examination nor simple stimulation could be expected to do so. By 1964, equipment for both stimulating and recording a nerve action potential (NAP) across a lesion in continuity had been assembled. This consisted of a Grass stimulator and a Tektronix oscilloscope with differential amplification. The idea to do this was based on earlier pioneering work recording NAP's in vitro done by others, on the review of the Lyons Woodhall slide collection and also on histologic observations on primate regeneration done at WRAIR at that time. ${ }^{15-19}$ In the early weeks after crush injury or what appeared to be a technically satisfactory suture repair in the primate, there were thousands of axons, some of them fairly mature reaching the distal stump. These axons had not grown very far down the distal stump and certainly had not reached muscle in any significant number.

Studies were done initially in intact dog nerve and subsequently in intact primate nerve in vivo. It was found that an NAP could be recorded and readily differentiated from a muscle action potential (MUAP). This could be done by placing stimulating and recording electrodes directly on nerve and separating the two sets of electrodes by at least $3 \mathrm{~cm}$. Recording could moreover be done in vivo without "killing" one end of the nerve and without immersing it in mineral oil or other foreign substance. Satisfactory stimulation and recording could also be done without isolation of nerve in a chamber and without an electrically shielded environment. Responses recorded in vivo were indeed transmitted NAP's because crushing nerve distal to the recording site still permitted recording of the response proving that it was not a MAP. As might be expected, crush of nerve between the stimulating and recording electrodes eliminated this transmitted NAP response.

In a series of experiments carried out at the University of Michigan between 1964 and 1966 in Dr. E. Crosby's lab and under the supervision of Dr. E. Kahn, a number of further observations were made. ${ }^{19}$ (1) NAP's could be recorded distal to crush site in primates by 6 weeks and in severed and sutured nerves by 8 weeks. (2) Responses could be correlated in a rough but satisfactory fashion with population counts of axons made at distal recording sites. (3) Regenerating NAP's recorded directly from primate nerve and without use of summation required several thousand or more moderate sized ( $>5 \mu$ in diameter) fibers with at least some early myelination.

Further primate NAP studies were completed at LSUMC between 1967 and 1969:20 (1) NAP's could be recorded from the distal stumps of regenerating crushed or sutured nerves weeks to months before evoked muscle action potentials (MUAP's) or other EMG evidence of regeneration could be recorded. (2) In a regenerating nerve, depending on the time interval between injury and/or repair, NAP's could be sequentially recorded down the distal stump of the nerve. As the number and size of the fibers decreased distally, the NAP amplitude decreased and usually its velocity slowed. Eventually, as the fiber count decreased more distally, the trace would flatten out.

Initial patient recordings were done in Ann Arbor in 1966 and these clinical studies have continued at LSUMC since 1967. Ability to record an NAP or not has been correlated with preoperative clinical and electrical loss and intraoperative gross and electrical observations. Operative recordings were also correlated with pathology of resected segment where no NAP was recorded and finally clinical outcome in terms of functional 
recovery. ${ }^{5.12 .21}$ Similar laboratory and clinical studies have been subsequently repeated and reported by many others. ${ }^{22-29}$

\section{Basic Considerations}

In healthy nerve, stimulation of a nerve fiber membrane produces a conducted impulse or NAP when stimulus intensity exceeds the fiber's threshold. ${ }^{16,18}$ Various axons which respond to lower intensity stimuli do so because of their membrane properties. ${ }^{30}$ Of interest, medium-sized fibers have the lowest threshold, then the large fibers and finally the fine or small fibers have the highest threshold. ${ }^{31.32}$ NAP amplitude can vary depending on the intensity of the stimulus and, therefore, the number of fibers stimulated. If the stimulus is supramaximal in intensity then NAP amplitude and its integral (area covered by the NAP) will be maximal. ${ }^{16}$

Threshold for stimulation and therefore ability to evoke an NAP depends on both the duration and magnitude of the applied stimulating current. Both of these parameters interact. If stimulus durations are shorter than the rheobase value, a compensatory increase in stimulus current is required to change membrane behaviour and produce the NAP. This interaction of stimulus duration and current is useful in differentially activating larger, myelated fibers as opposed to small, unmyelinated fibers. In addition to being less likely to activate small unmyelinated fibers the short-duration stimulus pulse also produces less stimulus artifact. Further, short-duration pulses are desirable since the clinical concerns need to be directed toward the status of medium or large, myelinated fibers at a stage of regeneration when these should be present in significant number at both the stimulating and recording sites. ${ }^{34}$ The finest unmyelinated fibers, including regenerating fibers, have a much higher threshold than large axons and may require substantially greater stimulation to evoke an NAP. ${ }^{30.32}$ Even high current stimulation may not evoke a response in some abnormal fibers without also increasing stimulus duration. ${ }^{33}$ Thus, many factors may influence the responsiveness of nerve fibers to electrical stimulation.

Nerve fibers embedded in scar or within tumor will require higher currents for stimulation since both the capacitance and resistance of such tissue tends to shunt the stimulus away from the neural tissue. Connective tissue surrounding nerve can also shunt current away from electrodes, particularly those used for recording. Thus, recording from a regenerating nerve may require not only higher stimulating current to evoke the response but also higher amplification to record it. Surrounding tissues can both reduce NAP amplitude and distort its form. Computer averaging may improve noise level and enhance the appearance of the evoked response but may not reflect function as accurately as a single trace. ${ }^{26} \mathrm{~A}$ minimal response, which would be associated with little or no clinically significant function, could be made 10 appear deceptively more significant through the process of averaging.

In a myelinated axon, impulse conduction occurs when a region of active membrane, often involving more than one node of Ranvier, excites adjacent nodes. The mechanism of "jumping" of the action potential in myelinated nerve is affected by the diameter of the axon, the thickness of myelin, and the distance between nodes. There is a remarkably constant proportional relationship between these three factors with various sized myelinated fibers. ${ }^{30}$ Thus, the distance between nodes, the thick- ness of myelin and the number of nodes responding as a unit, as well as axonal diameter, determine the axon's conduction velocity. Another factor in determining conduction velocity is the time required to reproduce the action potential at each node. The neuropathology of the neuropathy varies the conductive response. ${ }^{13}$ Distribution studies of conduction velocities have shown a relationship between NAP size and shape and the axonal composition of the whole nerve ${ }^{30}$ Certainly, the presence of a compound nerve action potential or cNAP indicates the presence of variable axons. Without extreme amplification or averaging, direct stimulation and recording seems to require at least 4,000 moderate to large fibers with some degree of myelination.

\section{Electrodes Used For NAP Stimulation And Recording}

Electrodes are made of either a noble metal such as platinum or medical grade stainless steel in order to minimize electrolysis associated with metal in contact.with nerve during stimulation. Eighteen guage wire is bent like a shepherd's crook on one end so that nerve can be suspended in the crook and gently lifted away from other tissues. The other ends of the wires are placed through the center of a drilled-out Delrin or Teflon rod and soldered to leads for attachment to instrumentation used for stimulating and recording. The drilled out center of the rod is then sealed with a surgical epoxy cement. When materials are carefully selected, the electrodes can withstand autoclaving, gas sterilization, and water absorption.

The ends of the two active electrodes used for stimulation are separated by at least $3 \mathrm{~mm}$. Electrode tips are separated by 5 to $7 \mathrm{~mm}$ stimulation on larger nerves such as sciatic or some brachial elements since a larger volume of tissue is involved. If electrode tips are spaced too closely, not all fibers will be stimulated. Stimulation of a nerve both in continuity and in situ differs from the classic physiologic recording in vitro or with one or both nerve ends killed. Some small but important alterations in electrode configuration are necessary.

If two stimulating electrode tips are used, there is not only a current generated in the gap between the two but also flowing

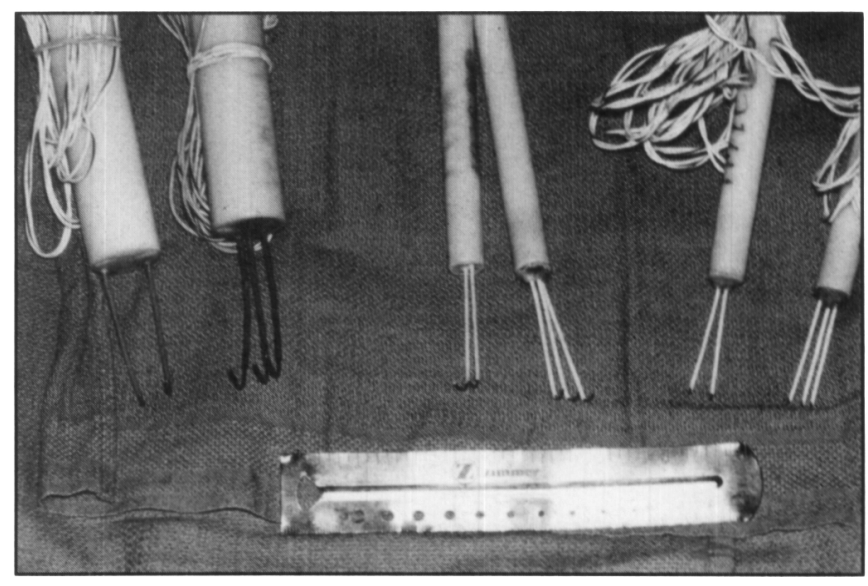

Figure I - Different sized electrodes used for NAP recording. Microelectrodes for digiral nerves or pediatric cases to the right. In the center are minielectrodes used for most adult cases and to the left macroelectrodes used for some adult nerves such as adult sciatic and femoral nerves and some plexus elements. Three-pronged stimulating electrodes are on the right in each of the three pairs and bipolar recording electrodes to the left. 
away from the electrodes through nerve as well as through other body tissues and back again to nerve. This shock is almost instantaneous but still tends to give a large stimulus artifact which outlasts the stimulus itself. When stimulating and recording montages are relatively close as they have to be in some clinical situations, the decay of this stimulus artifact can obscure the evoked NAP. One way to minimize this is to use three tips for the stimulating electrode as explained previously. ${ }^{34}$ The outermost two tips are a common anode and are connected one to the other while the middle tip is the cathode. Application of a potential difference between the outermost and innermost active electrodes still produces two current paths but neither involves the whole nerve and thus, the stimulus artifact is reduced. The tripolar stimulation electrode also limits the longitudinal spread of the stimulating current course in the nerve making for a more precise point of stimulation.

Recording electrode configuration is also important. The electrodes are bipolar and each wire or tip at the recording site is separated by 3 to $5 \mathrm{~mm}$ so that one electrode is recording from an active and the other from a relatively inactive portion of the nerve. If these two recording tips are too close together on the nerve, amplitude of the evoked NAP can be reduced or the NAP eliminated altogether. The greater the distance between stimulating and recording electrodes, the greater the need to separate the two bipolar prongs of the recording electrode by a greater distance. This is because, over longer recording distances, there is a greater length of active nerve due to greater temporal dispersion in conduction with the time of arrival of responses at the recording site being quite variable. This temporal dispersion is due to differences in conduction velocities amongst different sized, myelinated axons. If the distance between stimulating and recording electrode sets is too short, the stimulus artifact will still be extensive despite use of a tripolar stimulating electrode.

Connecting wires from the stimulating and recording electrodes should be separated by at least $30 \mathrm{~cm}$ or so if possible.

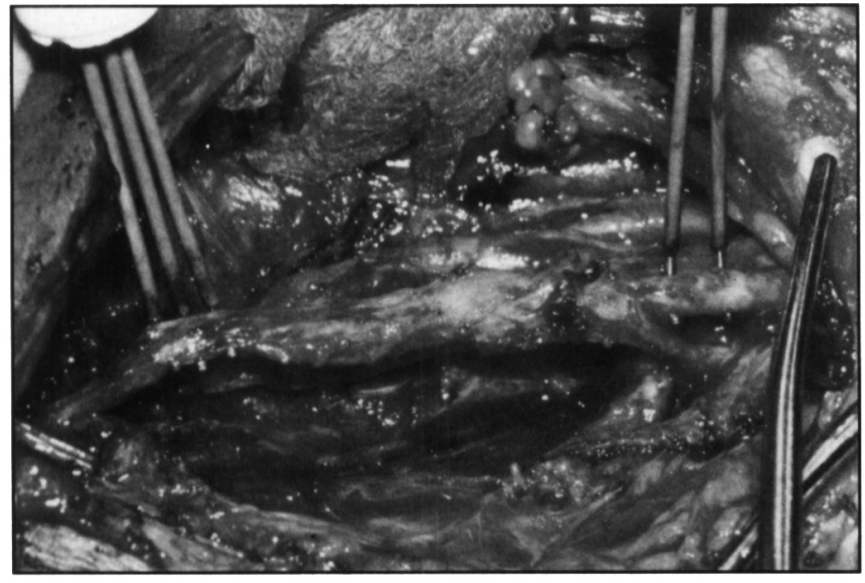

Figure 2 - Stimulating and recording from brachial plexus injured by stretch. The head is towards the left and clavicle to the right. Macroelectrodes are in use with three-pronged or tripolar stimulating electrodes to the left on the C5 spinal nerve and bipolar recording electrodes on the posterior division of the upper trunk. There was no NAP across this segment nor from C5 to anterior divisions or supraclavicular nerves. Traces were also flat for the C6 outflows to the divisions and supraclavicular nerve. As a result, this segment was resected and a repair done by sural grafts. The resected segment was neurotmetic or Sunderland Grade 4.
Otherwise capacitance between the wires can not only further increase stimulus artifact but also produce other electrical noise. ${ }^{34}$ Shielded wire is usually used to lead out from recording electrodes but not for the stimulating electrodes since isolation needs to be maximized. Electrode to wire connections and integrity of the wire can be readily checked by use of an OHM meter.

Grounding is provided by attaching the lead out from a bovie pad affixed to the patient's skin to the grounding portion of the recording machine. Of course, the electrosurgical unit is turned off to provide safe grounding and to reduce unwanted noise. Operating room equipment which is either battery operated or motor driven or fluorescent lights should be turned off or better yet be disconnected by having their outlets removed from nearby wall sockets. This reduces the possibility of 60 cycle interference.

\section{Stimulating And Recording Equipment Used}

Most electromyographic (EMG) machines manufactured within the last 15 years will have the necessary built-in stimulating and recording parameters for satisfactory NAP recording. In recent years we have found it convenient to use the TECA, model TD 20 which is self contained and provides some degree of flexibility. ${ }^{12.34}$ One can also construct a system using a Grass model stimulator (S-44) with a stimulus isolation unit (SIU-6) to provide stimulation. ${ }^{6}$ Recording can be done using an oscilloscope with a differential amplifier such as the Tektronix 7000 series. A trigger wire can be led from the stimulator to the oscilloscope so that a trace will be prompted with each stimulus delivered to the stimulating electrode(s).

Whether a compact EMG machine such as the TECA TD 20 or a larger system is used, attention must be paid to both the high and low frequency filters. The low frequency filter setting is usually placed in the 5 to $10 \mathrm{~Hz}$ range or lower and the highfrequency setting at $2500 \mathrm{~Hz}$ or higher. These settings tend to decrease stimulus artifact without filtering out the evoked NAP

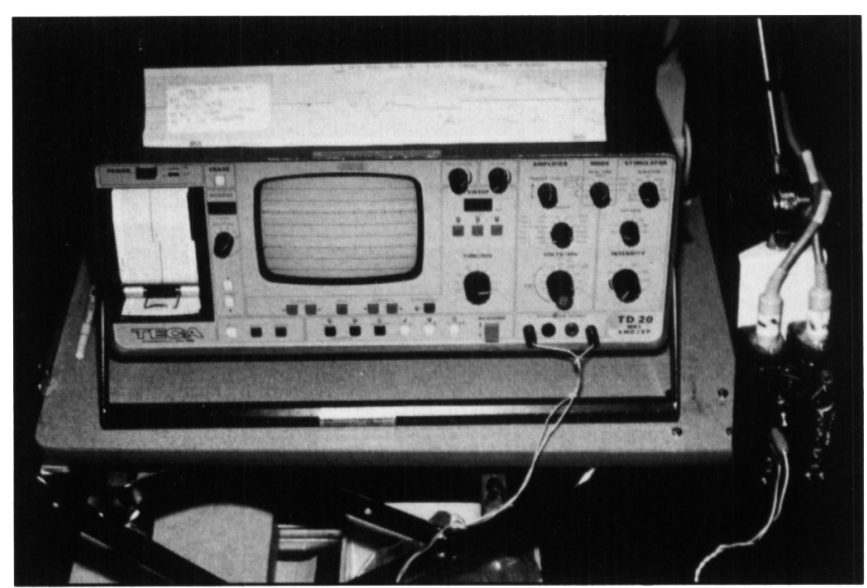

Figure 3 - Stimulating and recording machine which in this case is a TECA TD 20 EMG machine. Tracing from a stretched axillary nerve has been propped up on the top of the machine. Stimulating lead out wires are coming from posts at the right and bottom of the machine, while recording wires are plugged into the recording module to the right. Settings to record the axillary nerve trace where $100 \mu \mathrm{V}$ and $0.5 \mathrm{msec}$ per division with filters set at $200 \mathrm{~Hz}$ and 2 $\mathrm{KHz}$. Stimulation was approximately $85 \mathrm{~V}$ at $0.05 \mathrm{msec}$ duration at a rate of 2 per second. 
response. If overfiltered, the stimulus artifact will be greater and the amplitude and integral of the NAP less. If a $60 \mathrm{~Hz}$ notch filter is built into the recording instrument, it is usually better not to use it for NAP recording. The filter device itself can generate a wave resembling an NAP.

\section{Technique Used For Stimulating and Recording NAP's}

Short duration stimuli are used to both decrease stimulus artifact and to decrease stimulation of fine fibers which may or may not mature further with time and lead to useful function. Typical settings can be between 0.05 to $0.1 \mathrm{msec}$ in duration. This requires increased voltage for adequate stimulation. While healthy nerves may require voltages between 3 and $15 \mathrm{~V}$, regenerating nerve may need $50 \mathrm{~V}$ or more. Frequency should be kept at 2 per second or less to prevent damage to nerve with these short duration, high voltage stimuli.

NAP's are recorded with the oscilloscope set between $50 \mu \mathrm{V}$ and $5 \mathrm{mV}$ per division. Time base is set on 0.5 to $2 \mathrm{msec}$ per division. We usually begin by recording the NAP proximal to the injury site, both stimulating and recording above the injury. ${ }^{6}$ If the system is working and 3 to 4 or more centimeters can be exposed proximal to the lesion in continuity, a NAP response should be recordable. Recording electrodes are then moved onto the lesion site and beyond to see if an NAP can be recorded and, if so, how far distal to the injury site. If a proximal segment of the injured nerve is not available for a baseline recording, then an adjacent uninvolved nerve may be used to check the electrodes and the stimulation and recording settings. These settings can then be used as a starting point to stimulate and record from the injured nerve. Intensity of stimulation and, if need be, duration can be increased as well as amplification used for recording. There are cases, particularly when severe plexus stretch injuries are studied intraoperatively, where one cannot record from nerve proximal to injury site or even from other uninvolved or less involved nerves. ${ }^{12}$ One must then be content with stimulating at the lesion site or even distal to it and recording below or distally.

Response of distal muscle to stimulation of nerve proximal to a lesion is also noted since visible contraction usually indicates good regeneration not only through the lesion but to that muscle. In general though, in the early months post injury, unless the lesion was partial to begin with, such obvious evidence of sparing or recovery will usually not be present. The objective in operative recording is to measure a NAP distal to the lesion. In the initial 9 months after injury, the NAP's amplitude and conduction velocity are not as important as the simple presence or absence of a response. Presence of an NAP indicates axons of sufficient number, caliber and maturation to presage useful recovery of function for at least a portion of the injured cross section of nerve. Absence of an NAP indicates that recovery will not occur without resection and repair.

Visual inspection of the conducting segment, in some cases where a NAP is present, will suggest that one portion of the lesion's cross section is more severely injured than another. Then, the lesion can be split into bundles of fascicles and groups or individual fascicles tested. ${ }^{35}$ This will usually indicate that some fascicles or bundles conduct and others do not. This in turn leads to a "split repair" where a portion of the nerve is repaired by direct suture or graft(s) and a portion has neurolysis only.

As stimulation and recording begin, the stimulus intensity (voltage) is gradually increased and the amplification for record- ing is also increased until a NAP is seen. Different filter settings can also be tried. The stimulating electrodes are usually placed proximally and recording ones distally. A proximal stimulation site ensures activation of a maximal number of fibers. ${ }^{21.26}$ In addition, when a stimulus site proximal to the injury is accessible, more normal fibers can be stimulated proximally than distally. This decreases the need for a high-intensity stimulus and, as a result, decreases the stimulus artifact. The nerve is suspended in the crook of the electrodes and held away from other tissues or tissue fluids.

More distant evoked muscle action potentials (MUAP's) can be picked up by the recording electrodes placed on nerve. These responses, though, are quite delayed compared to NAP's. Thus, their calculated velocities are slow and are usually less than $20 \mathrm{~m} / \mathrm{sec}$. They are also larger in amplitude than NAP's and more likely to be polyphasic.

With a plexus lesion where spinal nerves or roots are injured at a preganglionic level but are intact postganglionically, rapidly conducting (60 to $80 \mathrm{~m} / \mathrm{sec}$ ) and relatively large amplitude NAP's can be recorded. This is due to the fact that the large and well-myelinated sensory fibers have been spared Wallerian degeneration and, when stimulated, conduct a rapid and large response. These responses differ from slower, lower amplitude regenerative NAP's and may even be faster and larger than those seen when recording from an intact plexus element. If there is doubt, the proximal part of the spinal nerve can be stimulated and an attempt made to record somatosensory evoked potentials. With preganglionic injury, these evoked responses will be absent.

If an extremity is operated on under tourniquet and the latter is inflated for 60 minutes or longer, the tourniquet should be left down for 20 or more minutes before NAP recording is tried. Ischemia as well as low wound temperature can block successful recordings. In several earlier cases done under tourniquet, NAP traces were flat and yet regeneration as shown by either histologic study of resected segment or subsequent clinical

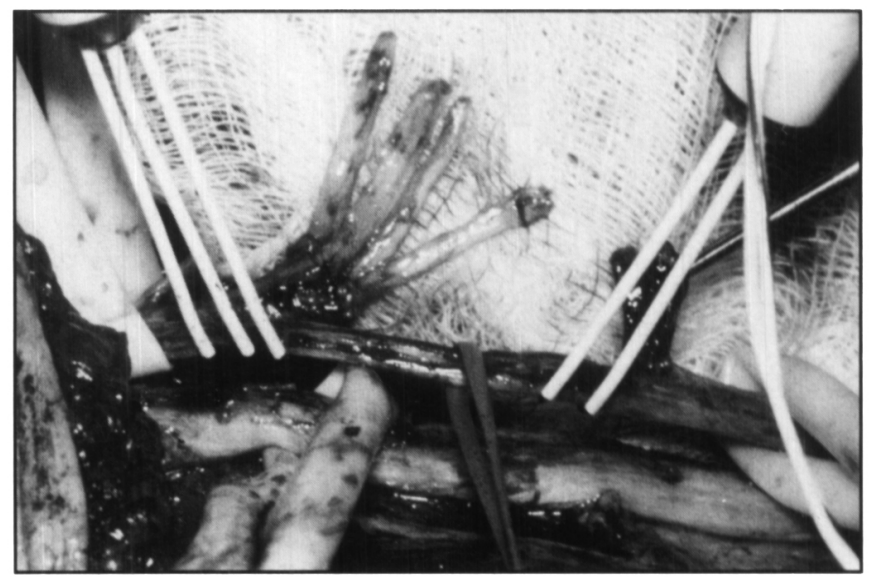

Figure 4-Example of a split repair of sciaric nerve at level of thigh. Tibial division had a good NAP and is genty retracted by a Penrose drain inferiorily. Stimulation (to the left) and recording (to the right) indicated need for resection of 4 fascicular bundles of the peroneal division. Sural grafts have been sewn into proximal portion of these bundles and are ready to be sew'n to peroneal bundles distally. The fascicles still in contimuity have electrodes on them and they had transmitted NAP's 
course was adequate. One also has to be careful of local anesthetic use because that may also temporarily block conduction. Block can persist for many hours so absence of an NAP may not under these circumstances indicate resection. On the other hand, muscle paralysis by curare-like drugs does not interfere with NAP recording.

\section{Results}

Recordings have been done on a large number of lesions in continuity. This has involved approximately 877 patients with upper and lower extremity nerve lesions, 432 with brachial plexus lesions in continuity, 245 tumors involving nerves, 617 entrapments, and 62 patients with cranial nerve palsies. As a result, intraoperative recording has been done in over 2,000 patients. This analysis does not include patients with pelvic plexus involvement, birth palsies or injuries to smaller nerves such as digital, antebrachial cutaneous, sural or saphenous. This analysis also does not reflect the fact that we often recorded from less involved or intact nerves or elements in the neighborhood of the more seriously injured nerve. This data is not included in this analysis since NAP recording was not used in those cases to determine partial injury or regeneration. NAP recording from these more intact nerves was either done out of interest or to ensure that our instrument settings for recording from the more seriously injured nerve were adequate.

Tables 1 through 3 delineate the results for upper and lower extremity nerves at different levels. Although loss associated with these lesions in continuity was usually complete both clinically and electrically before operation, there were exceptions in the upper and lower extremity lesions because some operations were necessary for severe pain or partial yet severe loss distal to the lesion. Thus, the percentage of median lesions felt to have complete distal loss before operation and intraoperative recording was $70 \%$. For radial nerve this figure was close to $74 \%$ and for ulnar lesions it was $68 \%$. For lower extremity nerves, preoperative loss was felt to be complete in $65 \%$. Although the majority of lower extremity nerve lesions had complete loss in their distribution(s) at the time of operation, there were important exceptions. Such lesions included injection injuries with incomplete loss but pain, GSW's associated with partial loss and yet pain, and a variety of other incomplete injuries affecting femoral or more distal tibial nerves. Brachial plexus lesions are listed as

Table 1. Criteria for Grading Whole Nerve Injury (LSUMC System)

0 (absent) No muscle contraction. Absent sensation.

1 (poor) Proximal muscles contract but not against gravity. Sensory grade $\mathbf{I}$ or 0.

2 (fair) Proximal muscles contract against gravity, distal muscles do not contract, sensory grade if applicable was usually 2 or lower.

3 (moderate) Proximal muscles contract against gravity and some resistance, some distal muscles contract against at least gravity, sensory grade was usually 3 .

4 (good) All proximal and some distal muscles contract against gravity and some resistance. Sensory grade was 3 or better.

5 (excellent) All muscles contract against moderate resistance; sensory grade was 4 or better. having complete or incomplete loss at the time of their evaluation and are tabulated as major elements involved and evaluated as well as cases operated on (see Table 4).

Patients with tumors involving nerve usually had little or no loss preoperatively. Intraoperative NAP recording was used to test fascicle(s), entering and leaving intraneural tumors and to check progress of the dissection in other cases. For example, in $68 \%$ of 69 solitary neurofibromas involving nerve, major function could be preserved despite total tumor removal by using intraoperative recordings and fascicular dissection.

As can be seen in Tables $2-5$, when a lesion was partial to begin with or more frequently had complete clinical loss and yet a recordable NAP, eventual recovery with neurolysis alone was excellent. Thus, $93 \%$ of nerves or elements having a recordable NAP and as a result neurolysis went on to a grade 3 or better recovery (see Table 1 for grading method). From another perspective, $82 \%$ had a grade 4 or 5 recovery which represents quite acceptable outcomes.

Table 2. In Continuity Cases Studied (1965 - 1990) Upper Extremity Nerves

\begin{tabular}{lcc}
\hline \hline & $\begin{array}{c}(+) \text { NAP }= \\
\text { Neurolysis/Result* }\end{array}$ & $\begin{array}{c}(-) \text { NAP }= \\
\text { Repair/Result }\end{array}$ \\
\hline Median & & \\
$\quad$ Upper arm & $23 / 22$ & $16 / 11^{\circ}$ \\
Elbow forearm & $25 / 24$ & $16 / 12^{\circ}$ \\
Wrist & $\underline{24 / 24}$ & $\underline{17 / 14}$ \\
& $72 / 70$ & $49 / 37$ \\
Radial & & \\
Upper arm & $30 / 28$ & $62 / 42+$ \\
Elbow & $10 / 09$ & $08 / 07$ \\
PIN & $05 / 05$ & $04 / 04$ \\
Forearm & $01 / 01$ & $04 / 02$ \\
SSR & $\underline{03 / 03}$ & $\underline{06 / 06}$ \\
& $49 / 46$ & $84 / 61$ \\
& $\mathbf{1 2 1 / 1 1 7}(\mathbf{9 7 \% )}$ & $\mathbf{1 2 3 / 9 8 ( 7 9 \% )}$ \\
\hline
\end{tabular}

*Result $=$ Those achieving a grade 3 or better result.

$\circ=1$ split repair

$+=2$ split repairs

Table 3. In Continuity Cases Studied (1965 - 1990) Upper Extremity Nerves

\begin{tabular}{lcc}
\hline \hline & $\begin{array}{c}(+) \text { NAP }= \\
\text { Neurolysis/Result* }\end{array}$ & $\begin{array}{c}(-) \text { NAP }= \\
\text { Repair/Result }\end{array}$ \\
\hline Ulnar & & \\
$\quad$ Upper arm & $17 / 16$ & $16 / 07^{\circ}$ \\
Elbow forearm & $45 / 43$ & $14 / 10^{\circ}$ \\
$\quad$ Wrist & $08 / 08$ & $08 / 05+$ \\
Combined median-ulnar & $40 / 36$ & $48 / 30^{\circ}$ \\
Combined median-radial & $11 / 08$ & $05 / 04$ \\
Combined median- & & \\
$\quad$ ulner-radial & $04 / 04$ & $08 / 06$ \\
& $\mathbf{1 2 5 / 1 1 8 ( 9 3 \% )}$ & $\mathbf{9 9 / 6 2 ( 6 1 \% )}$ \\
\hline
\end{tabular}

$*$ Result $=$ Those achieving a grade 3 or better result .

${ }^{\circ}=1$ split repair

$+=2$ split repairs 
Of equal importance is that when NAP's were absent and the lesion in continuity was resected, pathologic study confirmed that the lesion was always neurotmetic or Sunderland Grade 4. Such lesions have extremely poor or no potential for spontaneous regeneration that might lead to useful function.

Optimal timing for recording varies somewhat according to the mechanism of injury. ${ }^{5.7}$ It takes longer for significant regeneration even that recordable by direct NAP studies, to occur in lengthier lesions such as those produced by stretch and/or severe contusion. Thus, most fracture associated contusions and GSW's can be tested operatively at 2 to 3 months post injury while plexus stretch injuries are more reliably evaluated at 4 or 5 months. On the other hand, recording can be done as an adjunct to tumor resection at any time and can be used as an investigative tool for entrapment or compressive neuropathies at any point in the course of these disorders.

Table 4. In Continuity Cases Studied (1965 - 1990) Lower Extremity Nerves

\begin{tabular}{lcccc}
\hline \hline & \multicolumn{1}{c}{$\begin{array}{c}(+) \text { NAP }= \\
\text { Neurolysis/Result }\end{array}$} & $\begin{array}{c}(-) \text { NAP }= \\
\text { Repair/Result }\end{array}$ \\
\hline Sciatic & Tibial & Peroneal & Tibial & Peroneal \\
Buttock & $30 / 28$ & $28 / 23$ & $23 / 20^{\circ}$ & $19 / 06^{\circ}$ \\
Thigh & $38 / 36$ & $34 / 31$ & $37 / 33^{*}$ & $43 / 19^{\circ}$ \\
Tibial & $13 / 12$ & & $11 / 10^{\circ}$ \\
Peroneal & $34 / 30$ & $69 / 15^{*}$ \\
Femoral & $15 / 13$ & $14 / 07$ & \\
& $\mathbf{1 9 3 / 1 7 5 ( 9 0 \% )}$ & $\mathbf{2 1 6 / 1 1 0 ( 5 1 \% )}$ \\
\hline
\end{tabular}

$0=1$ split repair

* $=2$ split repairs

Table 5. Bachial Plexus In Continuity Elements Studied (1965 1990)

\begin{tabular}{|c|c|c|c|c|}
\hline \multirow{3}{*}{$\begin{array}{l}\text { Injury Mechanism } \\
\text { Lac. in continuity } \\
\text { (12) }\end{array}$} & \multicolumn{2}{|c|}{$\begin{array}{c}\text { (+) NAP }= \\
\text { Neurolysis/Result }\end{array}$} & \multicolumn{2}{|c|}{$\begin{array}{c}\text { (-) NAP = } \\
\text { Repair/Result }\end{array}$} \\
\hline & Complete & Incomplete & Complete & Incomplete \\
\hline & $10 / 09$ & $18 / 17$ & $15 / 10$ & $04 / 03$ \\
\hline GSW's (90) & $41 / 40$ & $47 / 44$ & $116 / 64 *$ & $08 / 07^{\circ}$ \\
\hline Iatrogenic $(30)$ & $18 / 17$ & $17 / 17$ & $32 / 23^{\circ}$ & $06 / 04$ \\
\hline $\begin{array}{l}\text { Stretch/Contusion } \\
\quad(300)\end{array}$ & $\begin{array}{c}93 / 84 \\
162 / 150\end{array}$ & $\begin{array}{l}102 / 96 \\
\mathbf{1 8 4 / 1 7 4}\end{array}$ & $\begin{array}{l}336 / 150^{\circ} \\
499 / 247\end{array}$ & $\begin{array}{l}45 / 28+ \\
63 / 42\end{array}$ \\
\hline $\begin{array}{l}{ }^{\circ}=1 \text { split repair } \\
+=2 \text { split repairs } \\
*=5 \text { split repairs }\end{array}$ & \multicolumn{4}{|c|}{$\begin{array}{l}\text { Complete = Complete loss in distribution of } \\
\text { one or more major elements preoperatively. } \\
\text { Incomplete = Incomplete loss of function felt } \\
\text { to be in the distribution of element tested. }\end{array}$} \\
\hline \multicolumn{5}{|c|}{ Table 6. Other In Continuity Cases Studied (1965 - 1990) } \\
\hline \multicolumn{3}{|c|}{ Intraneural Tumors of Brachial plexus } & \multicolumn{2}{|l|}{80} \\
\hline \multicolumn{3}{|c|}{ Intraneural Tumors of Other nerves } & \multicolumn{2}{|l|}{165} \\
\hline \multicolumn{3}{|l|}{ Entrapments } & \multicolumn{2}{|l|}{617} \\
\hline \multicolumn{3}{|c|}{ Cranial Nerve Injuries } & \multicolumn{2}{|c|}{$62(\mathrm{VII}, \mathrm{XI}, \mathrm{Xll})$} \\
\hline
\end{tabular}

Intraoperative recording has been of help in a relatively large number of patients with accessory palsy. Loss of function was usually iatrogenic and due to lymph node biopsy or removal of a neck lesion and inadvertent damage to nerve distal to its innervation of sternocleidomastoid muscle. When the lesion was in continuity, as it was in $26 \%$ of cases, operative NAP studies were done. This approach led to resection of about $50 \%$ of such accessory lesions in continuity. These proved to be neurotmetic or Sunderland Grade 4. The other accessory lesions in continuity had a neurolysis and had a good outcome (averaged post operative grade was 3.9 ).

Although not necessary for operative management of entrapments, NAP recordings were usually done and were interesting. A direct recording was first made proximal to the presumed entrapment site. Actual entrapment site was then defined by progressively moving the recording electrodes toward, into, and across the presumed entrapment site and more distally as well. From these studies, some conclusions could be drawn. Milder degrees of slowing were sometimes seen well proximal to an area of more severe conductive deficit. In only a few cases did this appear to be due to two separate lesions or what some have termed a "double crush syndrome". On the other hand, operative conduction across the area of entrapment was almost always more severely depressed than might have been predicted by the preoperative non-invasive studies. This may relate to the fact that distance between stimulus and recording sites was less at the time of intraoperative recordings than by non-invasive studies. These differences were usually most obvious in patients with elbow level ulnar entrapments and those with presumed entrapment of the peroneal nerve over the region of the head of the fibula.

There were only 5 examples of true distal cubital tunnel syndrome where ulnar nerve entrapment appeared clinically or electrically at the level of the two heads of flexor carpi ulnaris and distal to the olecranon notch. On the other hand, slowing of conduction with elbow level ulnar entrapment usually appeared to be maximal either just proximal to the olecranon notch or, more often, within the level of the olecranon notch itself. Thus, 341 of the 350 patients studied for ulnar entrapment at the level of the elbow had findings maximal just proximal to or in the notch. Also, of interest, were intraoperative recordings on patients with PIN entrapments. The area of maximal conductive abnormality, although usually beginning at the arcade of Frösch, appeared to extend beyond that level distally and beneath the actual volar head of the supinator itself.

Some unusual entrapments or functional lesions to nerve have been further documented by intraoperative recording. These have included radial nerve at the level of the long head of the triceps, median as well as ulnar entrapments by Struthers ligament, and an irritative as well as compressive sciatic lesion just below the buttocks crease due to hamstring hypertrophy. There were a much larger number of plexus spinal nerves where thoracic outlet syndrome was suspected and intraoperative recordings showed conductive defects. These areas of slowing were more dramatic on the lower roots especially $\mathrm{C} 8$ and $\mathrm{T} 1$ but at times $\mathrm{C} 7$ as well. Conductive defect in these cases began at a spinal nerve or spinal nerve to trunk level but not more distally. By comparison, conduction velocities and amplitudes recorded from $\mathrm{C} 5, \mathrm{C} 6$ and usually $\mathrm{C} 7$ roots were almost always greater than those in lower roots in the "true" thoracic outlet problems. 
In these cases there was often some weakness of hand intrinsic muscles in both the median and ulnar distributions.

\section{InFormation Provided by NAP RECORding}

NAP recording permits evaluation of nerve at an earlier time than does more simple nerve stimulation. Occasionally, a few hundred fibers will reach muscle and permit an evoked MUAP or weak muscle contraction to occur in response to stimulation and yet further reinnervation is poor. Under these circumstances, NAP recording shows absence of a response since it takes thousands of moderate sized fibers at least at the recording site for a recordable NAP. A few hundred fibers going by the neural recording site, even if they reach muscle, will not be picked up as an NAP unless high amplification, summation and integration of the added responses are done.

Somatosensory studies where recordings are made over plexus sites, spine (SEP), or contralateral scalp (ECR) do not provide the same information as directly recorded NAP studies. ${ }^{12}$ Non-invasive sites available for distal stimulation in plexus palsies are well distal to the site of injury which is presumed to be in continuity. Thus, such studies could not be expected to provide information about serious plexus injuries for many, many months where loss of function is severe or complete. In addition, SEP and ECR responses recorded at the spine and especially scalp level are naturally amplified by the cytoarchitecture of the central nervous system. Thus, in studies done in the rat it has been found that it only takes 100 or so fibers with connection to the central nervous system to record either a SEP or a ECR. Nonetheless, intraoperative, somatosensory studies are of value where there is a question of nerve root or spinal nerve connection to the spinal cord. Interestingly, with a little experience with NAP recordings, one can readily differentiate preganglionic sensory fiber conduction from regeneration of a partially or completely spared element. NAP responses associated with preganglionic injury are quite rapid, have high amplitude and require relatively low stimulus intensities to be evoked.

\section{REFERENCES}

1. Zachary R, Roaf R. Lesion in continuity. In: Seddon H, ed. Peripheral Nerve Injuries. Her Majesty's Stationary Office. Med Res Council Spec Report Series No. 282, 1954.

2. Gilliatt R. Physical injury to peripheral nerves: physiologic and electrodiagnostic aspects. Mayo Clin Proc 1981; 56: 361-370.

3. Seddon HJ. Surgical Disorders of the Peripheral Nerves. Baltimore: Williams \& Wilkins, 1972; 68-88.

4. Sunderland $S$. Nerves and Nerve Injuries, 2nd Edition. Edinburgh: Churchill-Livingstone, 1978; 70-79.

5. Kline DG. Hackett ER. Reappraisal of timing for exploration of civilian peripheral nerve injuries. Surgery 1975; 78: 54-65.

6. Kline DG, Hackett ER. The neuroma-in-continuity: a management problem. In: Wilkins RH, Rengachary SS, eds. Neurosurgery, New York: McGraw-Hill, 1984; 1864-1871.

7. Hudson A, Hunter D. Timing of peripheral nerve repair: important local neuropathologic factors. Clin Neurosurg 1977; 24: 392405.

8. Lyons W, Woodhall B. Atlas of Peripheral Nerve Injuries. Philadelphia: WB Saunders Co., 1949.

9. Woodhall B, Nulsen F, White J, Davis L. Neurosurgical implications. In: Woodhall B, Beebe G, eds. Peripheral Nerve
Degeneration. Washington DC: VA Monograph, U.S. Government Printing Office, 1957.

10. Grundfest H, Oester YT, Beebe GW. Electrical evidence of regeneration. In: Woodhall B, Beebe GW, eds. Peripheral Nerve Degeneration. Washington DC: U.S. Government Printing Office, 1956.

11. Kimura J. Electrodiagnosis in Diseases of Nerve and Muscle: Principles and Practice. Philadelphia: FA Davis, 1983.

12. Kline DG, Hackett ER, Happel L. Review of surgical lesions of the brachial plexus. Arch Neurology 1985; 43: 170-181.

13. Sumner A. The Physiology of Peripheral Nerve Disease. Philadelphia: WB Saunders Co., 1980.

14. Nulsen FE, Lewey FH. Intraneural bipolar stimulation: a new aid in the assessment of nerve injuries. Science 1947; 106: 301.

15. Collins W, O'Leary J, Hunt W, Schartz H. An electrophysiological study of nerve degeneration in the cat. J Neurosurg 1955; 12:39. 46.

16. Erlanger J, Gasser H. Electrical Signs of Nervous Activity. Philadelphia: University of Pennsylvania Press, 1937; 2-33.

17. Gutmann E, Sanders F. Recovery of fiber numbers and diameters in the regeneration of peripheral nerves. J Physiol 1943; 101: 489.

18. Hodgkin A, Huxley A. Currents carried by sodium and potassium ions through the membrane of the giant axon on Loglio. J Physiol 1952; 116: 449.

19. Kline DG, DeJonge BR. Evoked potentials to evaluate peripheral nerve injuries. Surg Gynecol Obstet 1968; 127: 1239-1250.

20. Kline DG, Hackett ER, May PR. Evaluation of nerve injuries by evoked potentials and electromyography. J Neurosurg 1969; 31 : 128-136.

21. Kline DG, Nulsen FE. The neuroma-in-continuity: its preoperative and operative management. Surg Clin North Am 1972; 52: 11891209.

22. Terzis J, Dykes R. Electrophysiological recordings in peripheral nerve surgery: a review. J Hand Surg 1976; 1: 52-66.

23. Zalis A, Rodriguez A, Oester Y, Maius D. Evaluation of nerve degeneration by means of evoked potentials. J Bone Jt Surg 1972; 54A: 1246-1253.

24. Vanderark G, Meyer G, Kline D, Kempe L. Peripheral nerve injuries studied by evoked potential recordings. Mil Med 1970; 135: 90-94.

25. Hudson AR, Trammer B. Brachial plexus injuries. In: Wilkins R, Rengachary S, eds. Neurosurgery, New York: McGraw-Hill Book Co., 1985.

26. Van Beek A, Hubble B, Kinkead L. Clinical use of nerve stimulation and recording. Plast Reconst Surg 1983; 71: 225-232.

27. Kaplan B, Friedman W, Gravenstein D. Intraoperative electrophysiology in treatment of peripheral nerve injuries. J Fla Med Assoc 1984; 71: 400-403.

28. Friedman $W$. The electrophysiology of peripheral nerve injuries. NS Clinics of NA 1992; (2) 1: 43-56.

29. McGillicuddy J. Clinical decision making in brachial plexus injuries. NS Clinics of NA 1992; (2) 1: 137-150.

30. Dorfman L, et al. Conduction Velocity Distributions: A Population Approach to Electrophysiology of Nerve. New York: WR Liss, 1981.

31. Dawson GD. The relative excitability and conduction velocity of sensory and motor nerve fibers in man. J Physiol (Lond) 1956; 131: 436-451.

32. Waxman SG. Physiology and Pathobiology of Axons. New York: Raven Press, 1978.

33. Gilliatt RW, Sears TA. Sensory nerve action potentials in patients with peripheral nerve lesions. J Neurol Neurosurg Psych 1958; 21: 109-118.

34. Happel L, Kline D. Nerve lesions in continuity. In: Gelberman R, ed. Operative Nerve Repair and Reconstruction. Philadelphia: JB Lippincott Co., 1991.

35. Williams HB, Terzis JK. Single fascicular recordings: an intraoperative diagnostic tool for the management of peripheral nerve lesions. Plast Reconstr Surg 1976; 57: 562-569. 